\title{
Dynamic Vista of Sustainable Green Public Spaces Network in Wonosobo
}

\author{
Intan Findanavy Ridzqo, Hasna Jamilah, Pauline Brajon
}

\begin{abstract}
Regional development always stimulates urbanization, growing demographic and generating needs of housing. In Kampung Sruni, an urban kampung settlement in Wonosobo Regency, Indonesia, people built new houses on the lands which are the remaining green pockets amidst the settlement. In addition, green space area aimed to maintain ecosystem balance are absent within the new house planning. The challenge of designing green space in built settlement is the availability of land which is many in quantity, scattered and relatively small in size. On the other hand, this kampung has been designated as urban tourism destinations in Wonosobo, promoting people, socio-cultural activities and the green valley landscape setting. This paper offers alternative architectural perspective to design green public space which engages community, culture and urban kampung landscape fabric. Together with inhabitants as local community, strategy to replenish the degrading green spaces was done by creating sustainable design for inhabitant's current and future need, environment and tourism. Interestingly, beside the main function as green public space, the spatial component arrangement of the designs creates various types of vista offering view of man-made, man-made and nature, and fully nature landscape. Moreover, topography along this green public spaces network would generate observer's body a motorically spatial experience.
\end{abstract}

Keywords : Green public space, network, vista, Wonosobo, tourism.

\section{INTRODUCTION}

Regional development always stimulates urbanization. Implemented by improving existing infrastructures or building the new ones, this development would bring a new image to the region, even change it to be a new city. Ideally, this shifting should raise new opportunities in economic sectors, meaning more various jobs with better wages [1] which attract people to come to the city. Demographic grows and generates needs of space for housing [2].

To fulfil the need for housing, people coming to the city with some family members prefer to buy land then build a new house on it. Many lands sold amidst the urban settlement in Indonesia, prior were large. By the time, it was sold plot by plot in smaller size by landowners. Whereas, these lands are

Revised Manuscript Received on January 10, 2020.

* Correspondence Author

Intan Findanavy Ridzqo*, Department of Architecture, Institut Teknologi Indonesia, South Tangerang, Indonesia. Email: intan.findanavy@iti.ac.id, intan.findanavy@gmail.com

Hasna Jamilah, Department of Architecture, Universitas Sebelas Maret Surakarta, Indonesia.

Pauline Brajon, Atelier du Rouget Group of Virage, Le Rouget, France. green space pockets. Moreover, when planning a new house, the new owner doesn't allocate some area within to replenish green space. Hence, lost of green space means to disrupt ecological balance, like rain water absorption and air exchange [3].

The phenomenon above is occuring in Kampung Sruni, Wonosobo Regency, Central Java, Indonesia. Kampung Sruni is an urban settlement located in the central area of regency government. This settlement is situated on a decline topography towards the southern rear perimeter. High density of building and lack of water catchment area cause soil under this built environment threatened. On the other hand, in Kampung Sruni lives people who are well-known for their traditional cultural performance, such as traditional music and dance. Another speciality of this settlement is its natural setting which is a panoramic view of green mountainous landscape strained on the eastern to the southern perimeter. By high significance of its people and location, this settlement has been planned as one of the urban tourism destinations in Wonosobo [4].

To meet the need of water catchment area amidst the settlement and infrastructure to support future tourism, green space should be developed in a sustainable way, for inhabitants, environment, and tourism [5] [6]. The challenge of creating green space in urban kampung is the availability of land which is many in quantity, relatively small in size, but scattered.

An architectural approach for developing green space needs not only to determine functional aspects, but also to capture engagement between people, culture, and landscape found in this kampung. An observer who is being in a room tends to explore view in front of him to observe entire space. Standing still, a frame that can be typically captured by the human eyes consists of the horizontal angle and the vertical angle. The maximum number respectively $54^{\circ}$ for the horizontal angle, $27^{\circ}$ upward and $10^{\circ}$ downward for vertical angle [7]. In this discussion, the maximum horizontal angle is carefully ignored, but replaced by the angle of exposure which more allows observer to allow panoramic view without being limited by bordering planes. However, the vertical angle is important to discuss due to sloping topography to rear which adequately provides view of man-made with natural landscapes, fully man-made or fully natural landscape [8]. The green spaces makes a network which is weaving series of views showing the life of people inherited to the environment of Wonosobo.

\section{METHOD}

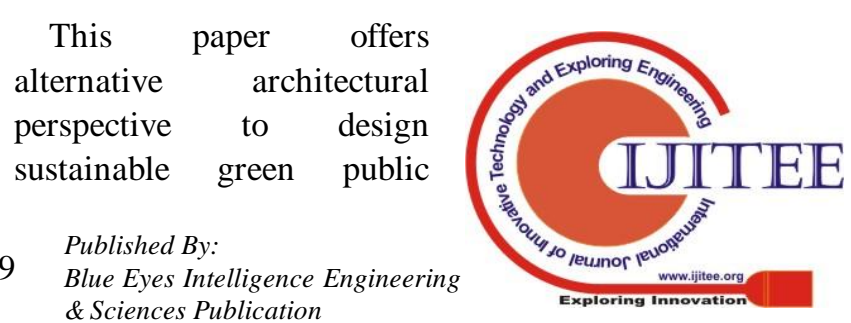


space which engages community, culture and urban kampung landscape fabric in Kampung Sruni, Wonosobo as well as to break down its spatial components arrangement in creating particular engaging vista. Explanation of the designers working processes starts the next part of the methods. It is followed by description of each green public design. On discussion part, this formation of green public designs is elaborated-assisted with literature of spatial arrangement - as one series of green public spaces which has the dynamic vista and how these togetherly raise sustainability for people, environment and economics opportunity from future urban tourism activities.

\section{A. Design Working Process}

In order to propose the most adapted scenario of sustainable development for Kampung Sruni, designers operated a concerted scheme comprised of four fundamental steps to uniquely design various public spaces (Fig. 1). It is critical to note that the public concerned in this project are various whom are inhabitants and visitors, such as tourists or travelers. The first step is global analysis of the kampung to make consensus of space and its usage, balanced between the perspectives of the district evolution and places of reference.

Secondly, designers did interviews informally on site as well as determined which existing open spaces need to be fortified and which sites in the kampung - an abandoned land or land with bad-stage house - have a potential for public use. Designer's task is to formulate the needs of public space dealing with possibility of investing abandoned places or bad-stage houses. The issue of density of houses [9] can be determined as a solution in the progressive opening of plots with old inhabited buildings.

Thirdly, designers met in the formal meeting with inhabitants to carry out fixation which sites would be operated and to hear what specificity of each new public space that they needed (Table-I). This step was an occasion to discuss more focus with the inhabitants or their representations about the outline of the designs formulation, so designers could refine the exact needs and connect these new public spaces and its connection within the settlement. Lastly, designers continued to work on each public space design. The final design flows from these specificities and designers' vision on environmental sustainability.

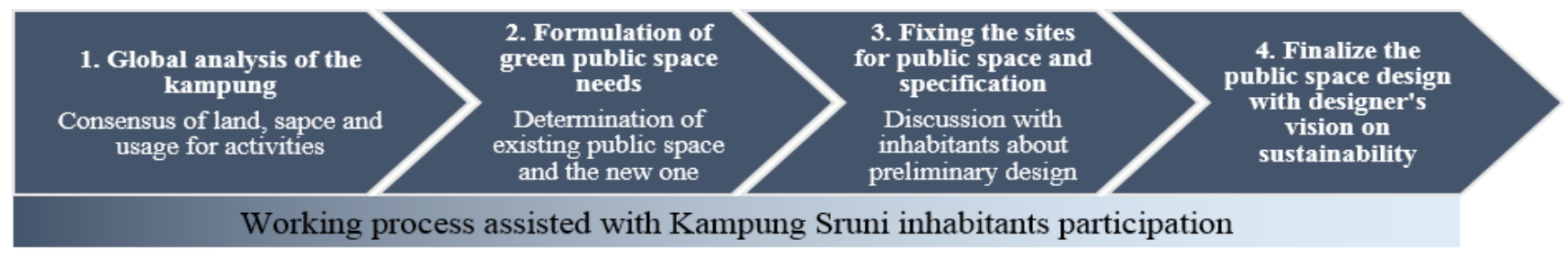

Fig. 1. Design working process flow.

Table-I. Land consensus in Kampung Sruni to be developed with green public spaces.

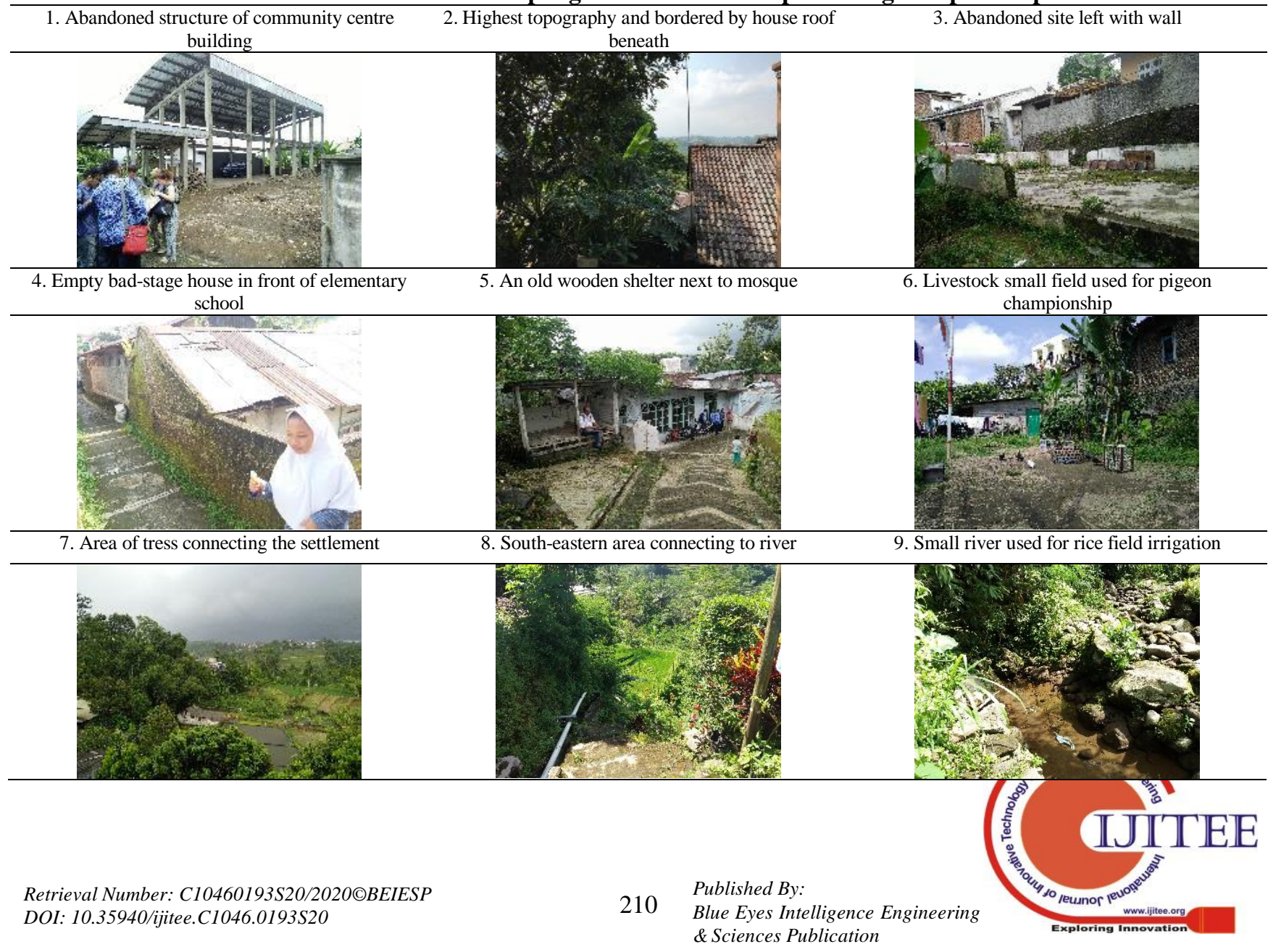




\section{RESULT}

Based on the result of consensus land intercepted with the need of public space, nine sites were selected (Fig. 2). These sites would be transformed into specific function of green public spaces (Table-II). By scattered location of sites, it is potentially making a network. By this network, these new public spaces are meant to be integrated into the net of existing public spaces, with a variable gradient of privacy for each one, that is the biggest ones and closest to public facility will be frequented for inhabitants and tourists, and the most hidden ones are meant to host sole inhabitant's need of gathering point.

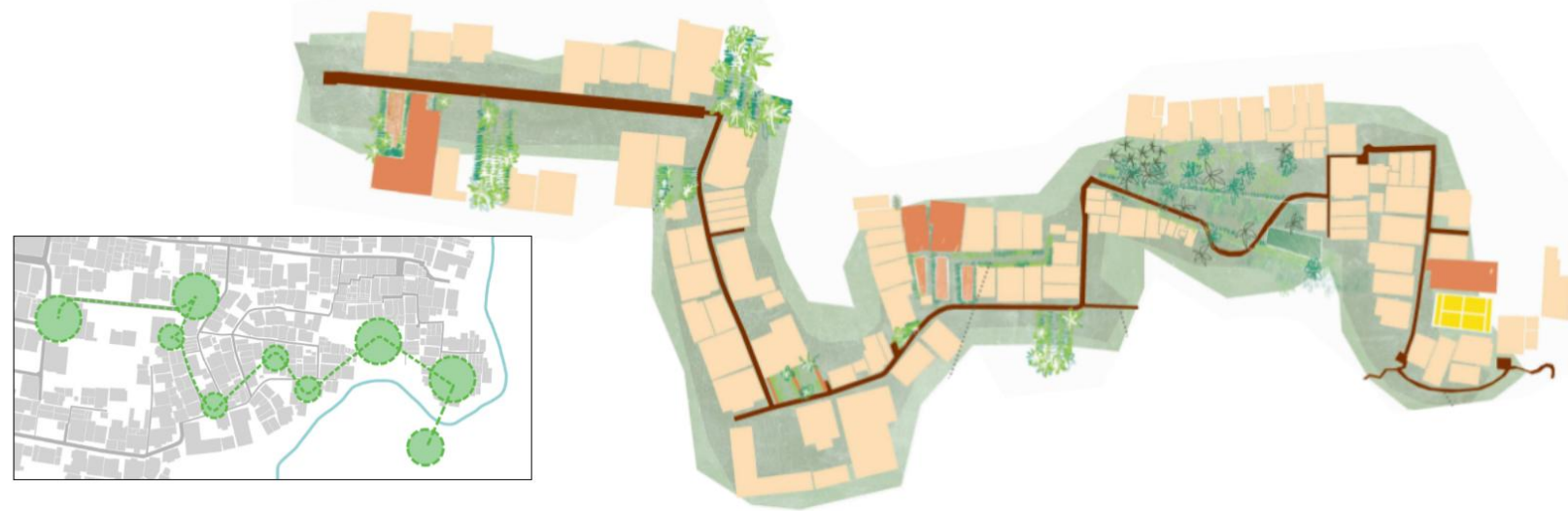

Fig. 2. Sites for public space in Kampung Sruni, Wonosobo make a linear network of green spaces.

Table-II. The proposed designs of nine green public spaces in Kampung Sruni.

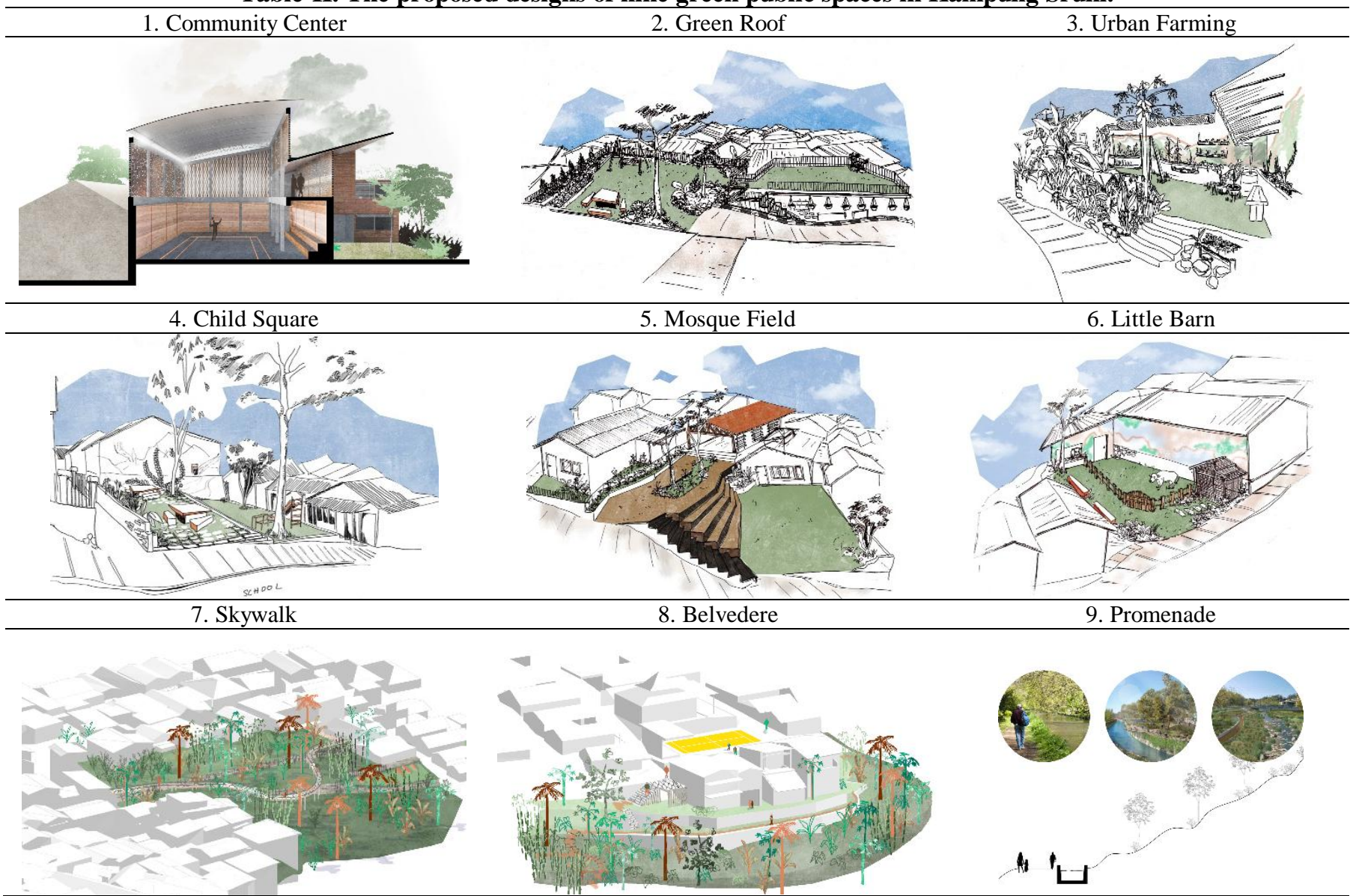

\section{A. Community Center}

The community center formerly already built. However, construction process has been postponed remaining only building's structural frame. Because of progressive needs by the inhabitants, the new design of community center is developed to accommodate extending programs, such as multifunctional room, praying room, meeting room, tourism office, learning center and also local dispensary.

\section{B. Green Roof - View Tower}

This prime spot properly starts the green public spaces network at Kampung Sruni. Getting into the settlement, a key node between prominent roads crossing an unoccupied land and a house roof beneath is potential because of high-frequency people commuting and its location 


\section{Dynamic Vista of Sustainable Green Public Spaces Network in Wonosobo}

on high topography level.

This pleasant spot adequately provides a full panoramic view of kampung's landscape. The new design is to modify rooftop as a green roof connected to the unoccupied land as large sitting point and view tower.

\section{Urban Farming}

Kampung Sruni inhabitants ordinarily do gardening in front of their house. They tackle problems of the limited space and sloping topography by arranging plants vertically with racks or hanging on retaining wall in front of their house. Inspired by this activity, to promote urban gardening in this kampung, an unoccupied site near to green sitting point are transformed to be a display of the urban farming activities.

\section{Child Square}

The specific site with an abandoned house located in front of elementary school is very potential to be developed for children spot. Building density spares no space for children to play and do outdoor activities after school. On this site, the bad-stage house building is demolished and transformed to be child square. This green public space would be deliberately fulfilled less furniture, only benches and table for discussion, so children can play freely in the large field.

\section{E. Mosque Square}

The local mosque is located in the center of the settlement. A multipurpose building next to the mosque was typically constructed to support mosque activities, but it is rarely used. Demolishing the bandoned building, the design applied on this area is to establish a wide-open field and stairs. This extensive space is aimed to adequately provide a large space for inhabitants gathering in the settlement's central area.

\section{F. Little Barn}

Some of Kampung Sruni inhabitants also raise livestock, such as cows and goats. The owners have nothing but small barn building on the small site within the settlement. This makes cattle rarely to get outside to grassing. An area next to the building, an expanded field routinely is used for pigeon championship. Therefore, this field is developed to be an interactive barn where provides space for cattle to grass and people could actively interact with it.

\section{G. Skywalk}

Uniquely situated on a declining steep land with mature trees, the skywalk is innovated to be uniquely a shortcut crossing the west and east area of the kampung. The green public space here is transformed by putting a bridge across it. As follows, the new infrastructure will be carefully constructed with minimum intervention to the fertile soil and alive trees under it. This iconic bridge will naturally bring experience walking on the Wonosobo mild air through the trees.

\section{H. Belvedere}

The topography on south-eastern perimeter of Kampung Sruni is a pretty slope than other back perimeter of the settlement. This perimeter area has been already constructed a structural retaining wall to reinforce the vulnerable sloping soil. This settlement's furthest area is uniquely a high belvedere facing towards natural mountainous exotic landscape in the rear of settlement. The proposed design on this belvedere is to transform it into multilevel belvedere which is meant to be more sloping and walkable for people.

\section{Promenade}

A promenade in Kampung Sruni is redesigned as a paved road located along the peaceful river beneath the back perimeter of settlement. This specific pathway had been built on the similar location for notable tourist attraction. However, the pathway has gone by the river's stream. The design of this new grand promenade allows local inhabitants to safely access the pristine river and their paddy field and directly heads tourist to the ultimate destination of this kampung that is a natural landscape of trees and river.

\section{DISCUSSION}

\section{A. Sustainable Public Spaces}

Fundamentally, green and public characters become main topics in adequately providing sustainable design of public space in Kampung Sruni. Necessary provision of these green space designs is to sufficiently restore the degrading environmental carrying capacity due to land shifting from open land to built environment. High density of building also causes people lack of public space to ordinarily do recreation around their adjacent environment. Furthermore, these prospective designs are envisioned as considerable preparation of essential infrastructures for future eco-tourism activities which is chosen as potential theme for tourism due to natural landscape surrounding [10].

\section{B. Dynamic Vista and Object Quality}

Beside specific function and location context, the dynamics of nine green open space designs are naturally created by its spatial components and aesthetic quality of visible object. Spatial components commonly found in settlement are vertical planes of house's wall and retaining wall; and horizontal plane which is universally site topography level. These planes sufficiently define space, moreover, naturally create the vista from inside to outside and vice versa Retaining wall or house wall may enclose the site of green public space on the left, right, or rear side. The less the wall bordering site, the wider the angle of the vista Simultaneously, the typology of object quality framed within the vista comprises of man-made, natural landscape, and mix of both (Table-III).

First green public trails in Kampung Sruni is started with a $360^{\circ}$ horizontal view located in the green roof. Strategically situated on the highest topography and without any buildings bordered its site, this green sitting allows the fullest panoramic sight of settlement landscape fabric. Going through into the settlement, observers will get green public spaces typically 
surrounded by alleys, houses, and walls. Bordered by walls, these public spaces have narrower vista to be seen from inside which is $180^{\circ}-270^{\circ}$ horizontal wide. The views provided here mostly are man-made of urban kampung life. Journey along green public spaces is ended on the promenade which has $360^{\circ}$ full view and natural landscape object.

Table-III. The typology of vista in nine green public spaces proposed design in Kampung Sruni.

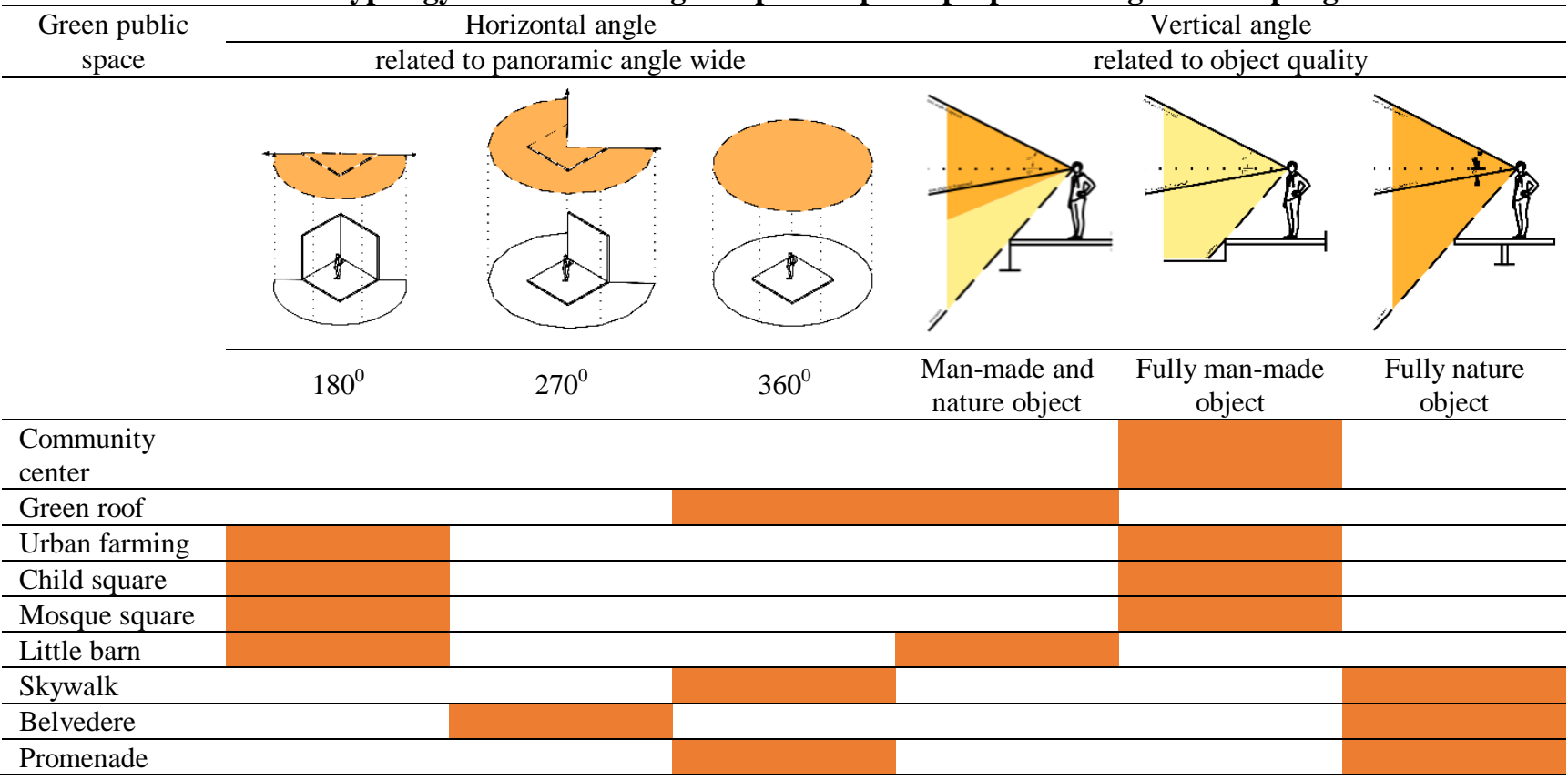

\section{Undirect Arrangement of Green Public Spaces Trail}

Scattered location of each green public space triggers movement from one public space to the next rises transition [11]. The declining topography brings journey through green public trails felt not only horizontally, but also vertically - that is upward and downward. Sequences of green public spaces also become surprising because it is concealed amidst the settlement and topography (Fig. 3). By the movements along the trail, the observers would get spatial experience visually and motorically.

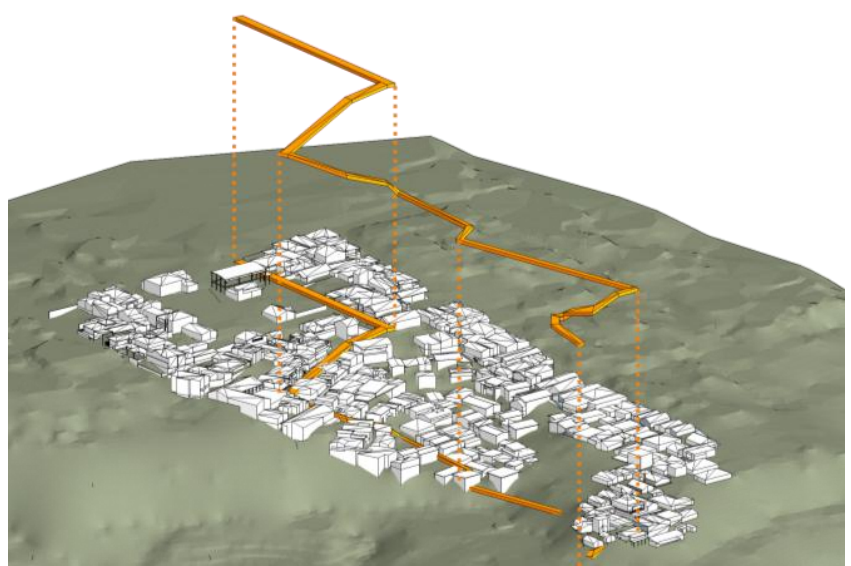

Fig. 3. Green public spaces trail in Kampung Sruni.

\section{CONCLUSION}

Local improvement of urban kampung should be meaningfully addressed as an essential part of developing sustainable urban space, taking into account its environmental carrying capacity. The green public spaces are carefully designed to implement sustainable development goals as well as to anticipate future urban eco-tourism activities. The architectural principles of ordering space to uniquely make a dynamic and contextual architectural space sequence respecting topography situation and landscape fabric. Therefore, these sustainable designs of public spaces are conceived as engagement of community with their culture, urban kampung space and natural landscape in Wonosobo.

\section{ACKNOWLEDGMENT}

This paper is written based on Batur team's work at the event of LCED International Workshop and Design Contest April 2018 held by Indonesia Ministry of Public Works and French ADEME. Gratitude also must be delivered to the students of INSA Blois participated in the event for their digital 3D modelling.

\section{REFERENCES}

1. B. D. Lewis, Urbanization and economic growth in Indonesia: good news, bad news and (possible) local government mitigation, Regional Studies, vol. 48(1), 2014, pp. 192-207.

2. S. Wilonoyudho, R. Rijanta, Y. T. Keban, \& B. Setiawan, Urbanization and Regional Imbalances in Indonesia, Indonesian Journal of Geography,vol. 49(2), 2017, pp. 125-132.

3. UNDP Indonesia. Sustainable Urban Development Strategy, 2017 Available: https://www.id.undp.org/content/indonesia/en/home/library/democratic g overnance/urban-strategy.html

4. Regional Government of Wonosobo, Rencana Pembangunan Jangka Menengah Daerah (RPJMD) Kabupaten Wonosobo 2016-2021 (Medium-Term Development Plan of Wonosobo Regency 2016-2021), 2016. 
5. I. Gunawan, S. Sagala, S. Amin, H. Zawani, \& R. Mangunsong, City Risk Diagnostic for Urban Resilience in Indonesia, World Bank Group, 2015. Available: https://openknowledge.worldbank.org/handle/10986/23771

6. C. Deuskar, J. L. Baker, \& D. Mason, East Asia's changing urban landscape: Measuring a decade of spatial growth. World Bank Publications, $2015 . \quad$ Available: http://documents.worldbank.org/curated/en/467661468248692758/EastAsias-changing-urban-landscape-measuring-a-decade-of-spatial-growth

7. E. Neufert, Architect Data Volume 1, Jakarta: Erlangga, 1992. p 32.

8. J. Specht, Architectural tourism: building for urban travel destinations, Springer, 2014, p. 18.

9. I. F. Ridzqo and P. Defaix, Tropical houses with economics activities consideration in Wonosobo, IOP Conf. Ser.: Earth Environ. Sci. Vol. 248 no. 1,2019

10. B. Maćkiewicz and B. Konecka-Szydłowska, Green tourism: Attractions and initiatives of polish Cittaslow cities in Tourism in the City, Springer, Cham, 2017, pp. 297-309.

11. M. G. Whitley, Architectural Narrative through Spatial Sequencing (doctoral dissertation), Virginia Tech, 2018.

\section{AUTHORS PROFILE}

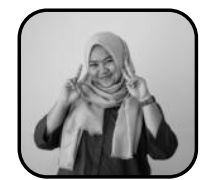

Intan Findanavy Ridzqo, is currently affiliated in Architecture Department of Institut Teknologi Indonesia, South Tangerang, Indonesia right after completing her master degree majoring on Architecture and Sustainability in Universitas Indonesia. Her published papers are in the area of architecture related to material and environment. Some researches have been conducted on vernacular architecture tectonic, dwelling environment, and material.

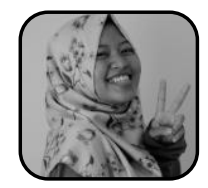

Hasna Jamilah, has been just finished her education in undergraduate program of Architecture Department Faculty of Engineering Universitas Sebelas Maret, Surakarta, Indonesia. She is now working for some voluntarily projects helping people and children affording better life and education.

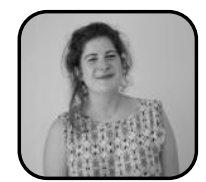

Pauline Brajon, was graduated for her master program in Institut National des Sciences Appliquées (INSA) Centre Val de Loire majoring landscape architecture. Her passionate then brought her currently to work as landscape architect in Atelier du Rouget, France. 